\title{
End-of-life decisions
}

Raanan Gillon Imperial College School of Medicine, University of London

Several papers in this issue of the journal and an important, though to some controversial, set of guidelines from the British Medical Association (BMA) warrant a return to the issue of withholding and withdrawing life-prolonging treatment including artificial nutrition and hydration (ANH) - in contexts where though they may prolong life they are judged incapable or highly unlikely to provide any health benefit to the patient concerned; or, in contexts where the patient has previously and competently refused such treatment. The Greek case described in this issue by Drs Garanis-Papadatos and Katsas tells of an 82-year-old woman in semi coma after a severe cerebrovascular accident (CVA) who in her first six weeks of hospitalisation repeatedly expressed her wish to die both by signs and a few uttered words, and by trying to remove the nasogastric feeding tube. ${ }^{1}$ Her children, aware of her lifelong aversion to hospitals asked the doctor about the possibility of withdrawing treatment. He was totally opposed, but after the patient's further deterioration into complete and irreversible coma the physician agreed to withdraw artificial nutrition while insisting on maintaining intravenous hydration. It was the most fundamental form of care and he as a doctor was obliged to provide it and his personal stance was supported by both medical and religious tradition. The patient survived two more weeks and died from a further CVA. The authors tell us that this doctor's views accord with those of the majority of Greek doctors. They also add that were a Greek prisoner undertaking a hunger strike to refuse artificial nutrition and hydration the prisoner's refusal would be honoured. (In this context the paper by Dr Brockman about hunger strikes by prisoners provides fascinating insights. ${ }^{2}$ )

Although they do not specifically address the issue of ANH Dr McHaffie and colleagues report on the considerable variation that exists across Europe in legislation and practice relating to withholding and withdrawal of life-prolonging treatment in the case of neonates who are either highly likely to die whatever treatment is given, or, (the source of more controversy) are likely to have severely impaired lives if they do survive. Among their important if unsurprising findings is that whether or not life-prolonging treatment is to be continued, all the countries studied agreed about the importance of maintaining high-quality compassionate care for the patient. ${ }^{3}$ Well is ANH to preserve life as long as possible a caring and compassionate thing to provide, regardless of whether or not any benefit to the patient's health will result, regardless of the patient's views or, where these are unclear, regardless of the views of those who know the patient well enough to be able to say what the patient is likely to have thought? The Greek doctor referred to by Drs GaranisPapadotos and Katsas clearly thought so in relation to artificial hydration, while somewhat inconsistently allowing withdrawal of artificial nutrition.

The BMA guidelines, at one with UK law, are at pains to reject this point of view. Keeping someone alive by ANH is not "basic care" it is medical treatment for patients who one way or another are unable to swallow. Furthermore the primary goal of medicine is not to keep patients alive as long as possible but rather "to benefit the patient by restoring or maintaining the patient's health as far as possible, maximising benefit and minimising harm". Usually, but not always, prolonging a patient's life who would otherwise die is a benefit for that patient. But if treatment, including life-prolonging treatment (LPT), would fail, or ceases, "to give a net benefit to the patient (or if the patient has competently refused the treatment) that goal cannot be realised and the justification for providing the treatment is removed". 4

The BMA emphasises that such an approach has nothing to do with euthanasia in the sense of intentionally killing a patient. Instead the intention of such withholding or withdrawing is to refrain from providing treatment that is not benefiting the patient. In this the BMA explicitly accepts that foreseeing the almost inevitable death of the patient if LPT is withheld or withdrawn 
does not entail intending that death. Instead it involves acceptance (by doctors, relatives and society more broadly) that we are all mortal and that in some fatal conditions no treatments including $\mathrm{ANH}$ - are of any benefit to the patient. And the BMA also emphasises this does not involve any judgments about the value of a patient's life - but does involve judgments about the value to a patient of a proposed or current treatment.

Opponents argue that nutrition and hydration, no matter how they are supplied to a patient, are never medical "treatments" - they are basic care and basic rights. The BMA, in line with UK law, rejects this claim. Some forms of providing food and water to those who are for some medical reason unable to swallow require medical techniques and skills for their implementation and/or provision and are properly classified as medical treatment. While the offering of food and water is basic care and should not be denied to those who can swallow food, for those who can't (or for whom normal feeding is unpleasant, for example because of choking) the issue should properly be: is the provision of $\mathrm{ANH}$ appropriate? And the answer should then properly turn on the question: will such ANH be beneficial to the patient's health?

Recognising the emotive and for some contentious nature of decisions to withhold - and particularly to withdraw - ANH, the BMA guidelines recommend additional precautions over and above those it recommends generally for decisions to withhold and withdraw LPT. These additional precautions include formal clinical review by a senior clinician who has experience of the condition from which the patient is suffering and who is not part of the treatment team; careful recording of the case, to be retained for further clinical review, and mechanisms for ensuring that all cases where the patient's wishes were not known are locally reviewed to check that appropriate procedures and guidelines have been followed.

And for all cases of withholding or withdrawing LPT - whether or not ANH is involved - the BMA guidelines recommend careful assessment of each individual case to ascertain whether the treatment in question will benefit the patient. In such assessment the patient's own views, preferably contemporaneous but when these are not available, previously established when competent, are preferable. When these are not available parents' views are especially relevant for children. For adults who have previously been competent to make their own decisions the role of family members anळ close friends is seen as providing evidence abour what the patient is likely to have considered to bo beneficial. For those who have never had capacitf. to make their own decisions "the primary facto will be the clinical benefits and burdens of the treatment" assessed as far as possible from the patient's point of view (as distinct from the prefer ences for themselves of the health care team or the family). "The views of those responsible for the continuing care of the patient, which would. include those close to the patient, should form an important part of that assessment".

In assessing whether provision of a LPT woule benefit a patient who is unable to advise the doc] tors either directly or indirectly, various factoris should be taken into account by the doctors whö are ultimately responsible for making the decisionis These include, so far as can be ascertained: the patient's own wishes and values; clinical judgment about the effectiveness of the proposed treatment, the likelihood of unmanageable pain or suffering the level of awareness the patient has of his or heo existence and surroundings as demonstrated fo example by the ability somehow to interact wit $\$$ others, and the capacity for self-directed action o $\overrightarrow{\vec{b}}$ the ability to take control of any aspect of hisolos her life; the likelihood and extent of anticipated improvement in the patient's condition if LP' provided; the degree of invasiveness of the LP T? the views of the parents if the patient is a child and the views of people close to the patient, espe $\frac{\Phi}{Q}$ cially close relatives, partners and carers, abou what the patient would consider to be beneficiag

The medical actions described by Drs Garanis= Papadatos and Katsas would surely be inconsiste ent with the BMA guidelines. It is difficult for this writer to understand how they could benefit oके "care for" or be in the interests of the patien? Should the time come for European guidelines, which approach should be recommended? Debate is invited.

\section{References}

1 Garanis-Papadatos T, Katsas A. The milk and the honey: eth ics of artificial nutrition and hydration of the elderly on the other side of Europe. Fournal of Medical Ethics 1990 25:447-50.

2 Brockman B. Food refusal in prisoners: a communication or 60 method of self-killing ? The role of the psychiatrist and resule ing ethical challenges. Fournal of Medical Ethics 1999; 25:451-

3 McHaffie H, Cuttini M, Brölz-Voit G, Randag L, Mousty Duguet A, et al. Withholding/withdrawing treatment fror neonates: legislation and official guidelines across Europẹ Fournal of Medical Ethics 1999;25:440-6.

4 British Medical Association. Withholding and withdrawind life-prolonging medical treatement. London: BMJ Books, 1999. O 